\title{
白严纪同褶波重磁化组分揭示中扬子褔皱带 构造旋转过程
}

\author{
张 辉 ${ }^{\mathbb{Q}}$ 谈晓冬 $\mathbb{1}^{*}$ 韩玉林 ${ }^{\mathbb{Q}}$ \\ (1) 中国科学院边缘海地质重点实验室, 中国科学院南海海洋研究所, 广州 510301; (2) 中国科学院研究生院地球科学学院, \\ 北京 100049.*联系人, E-mail: xdtan@scsio.ac.cn)
}

\begin{abstract}
摘要 为研究中扬子褶坡带的变形过程, 对重庆万州地区中三叠世灰岩和中晚侏罗世砂岩进行了古地 磁研究. 系统热退磁表明, 侏罗纪样品受现代地磁场重磁化严重, 三叠纪样品分离出 3 个重磁化组分: 低温 $\left(0 \sim 200^{\circ} \mathrm{C}\right)$ 、中温 $\left(200 \sim 360^{\circ} \mathrm{C}\right)$ 和高温 $\left(400 \sim 460^{\circ} \mathrm{C}\right)$ 组分. 低温组分分布于现代地磁场方向附近, 可能 为黏滞剩磁. 逐步展平褶皱检验显示: 中温组分在褶皱展平至 $33 \% \pm 8 \%$ 时获得, 相应古地磁方向为 $D_{\mathrm{ec}}=$ $11.2^{\circ}, I_{\mathrm{nc}}=45.2^{\circ}\left(\alpha_{95}=4.5^{\circ}, N=34\right)$, 对应古地磁极位置 $79.3^{\circ} \mathrm{N}, 219.5^{\circ} \mathrm{E}\left(d_{\mathrm{p}}=3.6^{\circ}, d_{\mathrm{m}}=5.7^{\circ}\right)$; 高温组分 在褶䏢展平至 $50 \% \pm 27 \%$ 时获得, 在 $95 \%$ 置信范围内取褶波展平至 $70 \%$, 相应古地磁方向为 $D_{\mathrm{ec}}=24.2^{\circ}$, $I_{\mathrm{nc}}=49.0^{\circ}\left(\alpha_{95}=3.6^{\circ}, N=23\right)$, 对应古地磁极位置为 $69.2^{\circ} \mathrm{N}, 195.5^{\circ} \mathrm{E}\left(d_{\mathrm{p}}=3.1^{\circ}, d_{\mathrm{m}}=4.8^{\circ}\right)$. 与白严纪参考 古地磁方向或极位置比较, 上述重磁化组分揭示该地区在褶皱变形的中期经历了 $12.8^{\circ} \pm 3.5^{\circ}$ 的顺时针旋 转, 而变形后期以来没有发生旋转. 结合前人数据, 认为中扬子褶皱带万州-香溪段部分弯曲是由弯山 构造引起的; 湖北蒲圻地区在裪䏢变形末期以来经历了 $27.5^{\circ} \pm 5.8^{\circ}$ 的顺时针旋转, 因此至少 $50 \%$ 的构造 旋转是由于弯山构造导致的. 中扬子褶皱带发生于侏罗纪末期和早白严纪的褶皱造山事件也揭示了华 南-华北地块碰撞可能一直持续到早白亚纪早期.
\end{abstract}

\section{关键词 重磁化 弯山构造 扬子褶䏢带 华南地块 古地磁 三叠纪}

褶皱造山带的走向通常存在一定程度的变化, Carey ${ }^{[1]}$ 将其定义为 orocline, 我们引用前人的译词, 即弯山构造 [2]. 古地磁研究揭示, 有些造山带经历了 差异性构造旋转从而导致其褶坡轴走向的变化, 而 有的没有显著的旋转过程. Marshak ${ }^{[3]}$ 特别地将前者 定义为弯山构造. 古地磁学方法被广泛用来鉴别弯 山构造, 其实也是对褶皱造山带构造变形过程的研 究. 扬子褶皱带也存在显著的褶波轴走向的变化: 在 上扬子地区, 褶䏢轴以北东一南西向占主导, 中扬子 地区逐步转为偏东一西或东一西走向, 到下扬子地 区则又以北东一南西(略偏南一北)走向为主(图 1). 扬子褶䏢带的形成与演化一般认为与华南(广义, 泛 指中国南方大陆地块, 包括扬子和华南地区)-华北地 块的碰撞拼贴相关; 两地块在东部首先碰撞, 然后自 东向西呈剪刀型相对旋转 ${ }^{[4]}$ 而形成的这一碰撞拼贴 模式为大多地质学者接受. 然而, 对于与这两地块碰 撞拼贴相关的扬子褶狓带的构造演化过程却存在不 同的认识.
对于扬子褶皱带弧形弯曲的成因, 国内外学者 自 20 世纪 80 年代中后期以来进行过不少研究和探讨. Steiner等人 ${ }^{[5]}$ 根据四川东北部广元等地区晚二叠-早 三叠磁性地层学研究得出的古地磁方向提出该研究 区域部分地区褶波走向的变化是由构造旋转造成的. 湖南洪家关早三叠世大冶组的古地磁研究也表明了 显著的旋转变形 ${ }^{[6]}$. Huang和Opdyke ${ }^{[7]}$ 对湖北巴东和 湖南桑植中三叠世红层的古地磁研究亦显示 $15^{\circ}$ 到 $30^{\circ}$ 的顺时针旋转, 且此两处的古地磁偏角与褶皱轴 延伸方向一致, 从而认为中扬子褶皱带走向的变化 是由构造旋转形成, 并指出可能是推覆带引起的局 部旋转, 但更倾向于整个造山带的折曲. 然而, 随后 从湖北远安附近中三叠世巴东组获得的数据 ${ }^{[8]}$ 却没 有显示明显的旋转, 由于此处属于前陆强烈褶皱推 覆带, 更接近秦岭造山带, 作者认为所观测到的扬子 褶䏢带的构造旋转并非是扬子地块与华北地块碰撞 的结果, 而是由于扬子地块与华南(狭义)地块的碰撞 拼合 ${ }^{[9]}$ 或者太平洋板块的俯冲 ${ }^{[7,8]}$ 引起的. Yang 


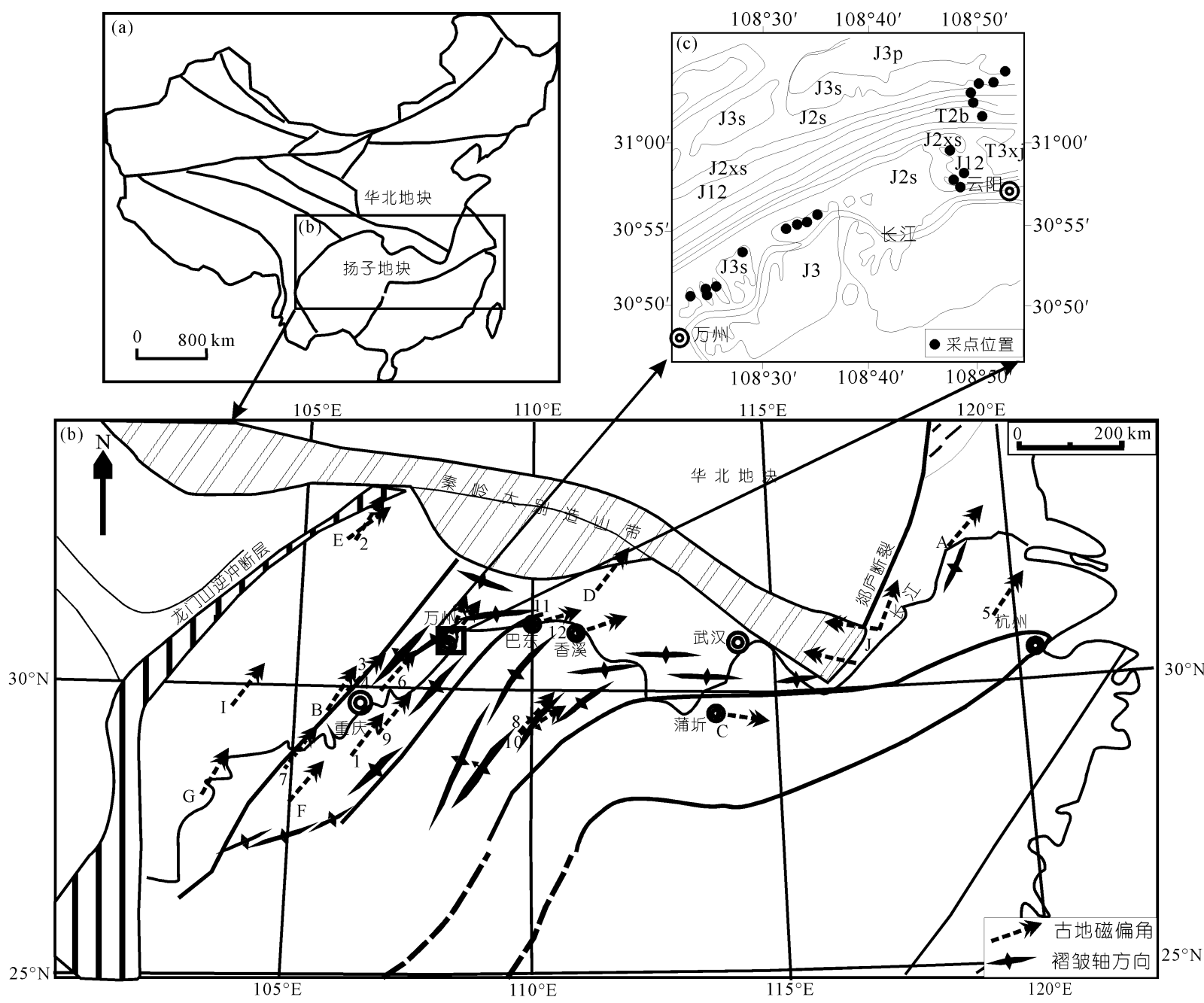

图 1 华南板块构造略图

(a), (b)修改自文献 [12]，(b) 中数字和字母与Tan等人 ${ }^{[11]}$ 的表示一致, 代表分析的古地磁数据

和Besse $\mathrm{E}^{[10]}$ 通过对扬子褶䏢带各研究区的古地磁偏角 与褶皱走向的对比, 没有发现两者间的直接关系, 为 此指出, 扬子褶皱带的弯曲不是造山折曲. Tan等人 [11]分析的结果却显示扬子褶䏢带多数采样区的古地 磁相对旋转量与褶皱走向有显著的相关性, 认为这 或许是弯山构造的证据, 但由于缺乏关于构造旋转 发生年代的约束, 尚需开展深入的研究.

综上, 中扬子褶皱带一些地区曾经历过显著的 构造旋转, 另一些地区可能没有明显的构造旋转. 造 成局部旋转甚至是整个造山带折曲的原因需要进一 步详细的工作. 前人的研究主要集中在二叠系与三 叠系, 为了更好地约束古地磁旋转的年代, 我们对中 扬子褶皱带重庆万州地区三叠系和侏罗系进行了详 细的古地磁研究.

\section{1 地质背景和采样}

重庆万州地区处于中扬子褶皱带由北东向转为 东西向的过渡地带(图 1(b)(c)), 构造走向存在较大的 变化(褶䏢轴走向由 $\mathrm{NE} 60^{\circ}$ 向东逐渐变为近东西向), 是检验弯山构造的理想地区. 同时该地区靠近华南华北地块的碰撞带, 向北约 $100 \mathrm{~km}$ 便是秦岭-大别造 山带的南缘, 华南板块的北部边缘一房县-广济大 断裂 ${ }^{[13,14]}$, 其构造变形显然是由华南-华北地块碰撞 所致, 因此, 古地磁结果也能检验扬子褶皱带构造旋 转的成因.

本区内三叠世早期以浅海相碳酸盐岩沉积为主, 中晚期逐渐过渡为以碎屑岩为主夹碳酸盐岩的河流 三角洲相沉积 $[15,16]$. 中三叠世巴东组主要为灰色中 至厚层状灰岩; 侏罗系分布于向斜核部, 下统为含煤 
碎屑岩, 中上统为红色砂岩 ${ }^{[15,16]}$. 研究区域晚白严世 正阳组与下伏晚侏罗世蓬莱镇组不整合接触 $[15,16]$, 表明研究区域最近的褶皱变形活动发生在白严纪.

本次研究在巴东组灰岩倾角较陡 $\left(50^{\circ} \sim 70^{\circ}\right)$ 的背 斜北翼 9 个采点, 中侏罗系厚层砂岩聂家山组、下沙 溪庙组、上沙溪庙组 8 个采点, 晚侏罗世遂宁组、蓬 莱镇组 54 个采点(图 1(c)), 用便携式汽油钻机共采集 古地磁定向岩芯 449 块, 所有岩芯采用磁罗盘定向.

\section{2 古地磁结果}

样品测试在中国科学院南海海洋研究所新建成 的古地磁实验室屏蔽房内(残余磁场小于 $300 \mathrm{nT}$ ) 完 成. 每块岩芯被切割成 2 个或 3 个 $22 \mathrm{~mm}$ 长的古地磁 标准样品. 样品的剩磁都是通过 $2 \mathrm{G}$ 公司生产的三轴 低温超导磁力仪测得. 每个样品都经过逐步热退磁 (采用Schonstedt退磁炉, 磁清洗平均在 15 个温度点 以上)或者交变退磁. 退磁数据通过主成分分析 来确定各样品不同的剩磁组分, 然后以采点为单位, 通过Fisher统计 ${ }^{[18]}$ 最终获得各剩磁组分的平均方向. 数据处理使用了 Randy Enkin博士的古地磁分析软件 Paleomagnetism Data Analysis Version 4.2 (http://gsc. nrcan.gc.ca/sw/paleo_e.php ).

\section{1 中三叠系结果}

样品天然剩余磁化强度除 2 个采点在 $0.4 \sim 1.2$ $\mathrm{mA} / \mathrm{m}$, 其余都在 $2.44 \sim 7.87 \mathrm{~mA} / \mathrm{m}$. 交变退磁分离出 两个分量, 且当交变场峰值高于 $100 \mathrm{mT}$ 时剩磁方向 紊乱(图 2 中的 C084). 热退磁加热至 $480^{\circ} \mathrm{C}$ 以上剩磁 方向呈随机分布. 通过非磁滞剩磁实验, 获得矫顽力 谱的分布(图 3), 结果显示仅有一个低矫顽力的峰值, 说明磁性矿物以多畴颗粒为主. 综上热退磁、交变退 磁和非磁滞剩磁的结果表明, 携磁矿物主要为多畴 磁铁矿系列.

热退磁分离出 3 个组分(图 2). 低温分量在 $230^{\circ} \mathrm{C}$ 以下 9 个采样点的样品均被分离出来, 在地理坐标下 平均方向为 $D=1.4^{\circ}, I=49.6^{\circ}, k=266.4^{\circ}, \alpha_{95}=3.2^{\circ}$, 在 99\%置信范围内显然是现代地磁场(当地地磁偏角和 倾角为 $\left.D / I=-2.4^{\circ} / 47.3^{\circ}\right)$ 的重磁化. 6 个采点的样品在 200 $360^{\circ} \mathrm{C}$ 之间, 中温分量被分离出来, 地理坐标下 方向为 $D=13.6^{\circ}, I=65.5^{\circ}, k=132.3, \alpha_{95}=5.8^{\circ}, N=$ 34(表 1). 通过Watson和Enkin褶皱检验 ${ }^{[19]}$ 模拟，在 $95 \%$ 置信水平内褶皱展平至 $33 \% \pm 8 \%$ 时，精度参数 $k$ 达到最大值 $k_{\text {max }}=226.5$, 此时偏角和倾角为 $D=11.2^{\circ}$, $I=45.2^{\circ}\left(\alpha_{95}=4.5^{\circ}\right)$, 对应古地磁极位置 $79.3^{\circ} \mathrm{N}$, $219.5^{\circ} \mathrm{E}\left(d_{\mathrm{p}}=3.6^{\circ}, d_{\mathrm{m}}=5.7^{\circ}\right)$ 在 $95 \%$ 置信范围内与华 南板块白亚纪参考极位置一致. 在 $400 \sim 460^{\circ} \mathrm{C}$ 间, 5 个 采点的样品分离出了高温组分(表 1, 图 2), 地理坐标 下方向为 $D=102.5^{\circ}, I=80.4^{\circ}, k_{\mathrm{g}}=188.2^{\circ}, \alpha_{95}=5.6^{\circ}$, $N=23$, 地层坐标下为 $D=20.9^{\circ}, I=31.9^{\circ}, k_{\mathrm{s}}=237.7^{\circ}$, $\alpha_{95}=5.0^{\circ}$ (表 1). 通过Watson和Enkin褶皱检验 ${ }^{[19]}$ 模拟, 在地层逐渐展平至 $50 \% \pm 27 \%$ 时, 精度参数 $k$ 达到最大 值 $k_{\max }=540.8$ (因此这一高温分量并不是褶皱变形前 岩石所获得的古地磁方向), 相应的古地磁方向为 $D=$ $28.4^{\circ}, I=59.0^{\circ}\left(\alpha_{95}=3.3^{\circ}\right)$, 相应古地磁极位置 $65.4^{\circ} \mathrm{N}, 170.0^{\circ} \mathrm{E}\left(d_{\mathrm{p}}=3.7^{\circ}, d_{\mathrm{m}}=4.9^{\circ}\right)$.

\section{2 侏罗纪样品结果}

所采侏罗纪样品中, 仅中侏罗世一半采点和晚 侏罗世 14 个采点分离出低温和高温 2 个组分. 低温 组分为现代地磁场的重磁化, 高温组分受重磁化叠 加严重, 没有通过褶皱检验, 不能确定其形成的年代, 仍需进一步研究, 在此不再赘述.

\section{3 讨论}

岩石重磁化主要是由热活动导致热黏滞重磁化, 流体活动导致化学重磁化以及岩石应变等构造作用 所致. 中三叠系巴东组古地磁结果, 虽未能得到原生 剩磁分量, 但分离出 2 个具有重要意义的重磁化分量. 采样地区靠近秦岭造山带南翼, 褶皱轴迹沿东西向 展布, 显然本次研究发现的重磁化与华南-华北地块 的构造碰撞拼合有关. 结合本文获得的同褶皱重磁 化组分与前人已发表的有关数据, 我们来探讨中扬 子褶皱带的构造变形.

\section{1 中扬子褶䏢带弯山构造的存在}

中温分量由地理坐标校正到地层坐标, 精度参 数 $k$ 由 132.3 降至 60.7 (表 1), 显然不是褶皱前获得. 褶皱展平至 $33 \% \pm 8 \%$ 精度参数 $k$ 达到最大值, 说明此 重磁化分量获得于褶皱中后期. 由前述本地区地质 概况, 褶皱变形发生在晚侏罗世到早白严世. 相应古 地磁极位置 $79.3^{\circ} \mathrm{N}, 219.5^{\circ} \mathrm{E}, d_{\mathrm{p}}=3.6^{\circ}, d_{\mathrm{m}}=5.7^{\circ}$, 在 95\%信范围内与华南板块白严纪参考极 ${ }^{[20]}$ 位置一致 (图 4). 这说明强烈的褶皱变形后期导致岩石重磁化 以来本地区基本没有发生旋转.

由前述, 高温组分亦不是原生剩磁, 由地理坐标 转换到地层坐标(表 1) 精度参数 $k$ 没有明显提高. 在 岩层逐渐展平至 $50 \% \pm 27 \%$ 时, 精度参数 $k$ 达到最大 值 $k_{\text {max }}=540.8$, 可以肯定这一磁组分也是在褶怶变 

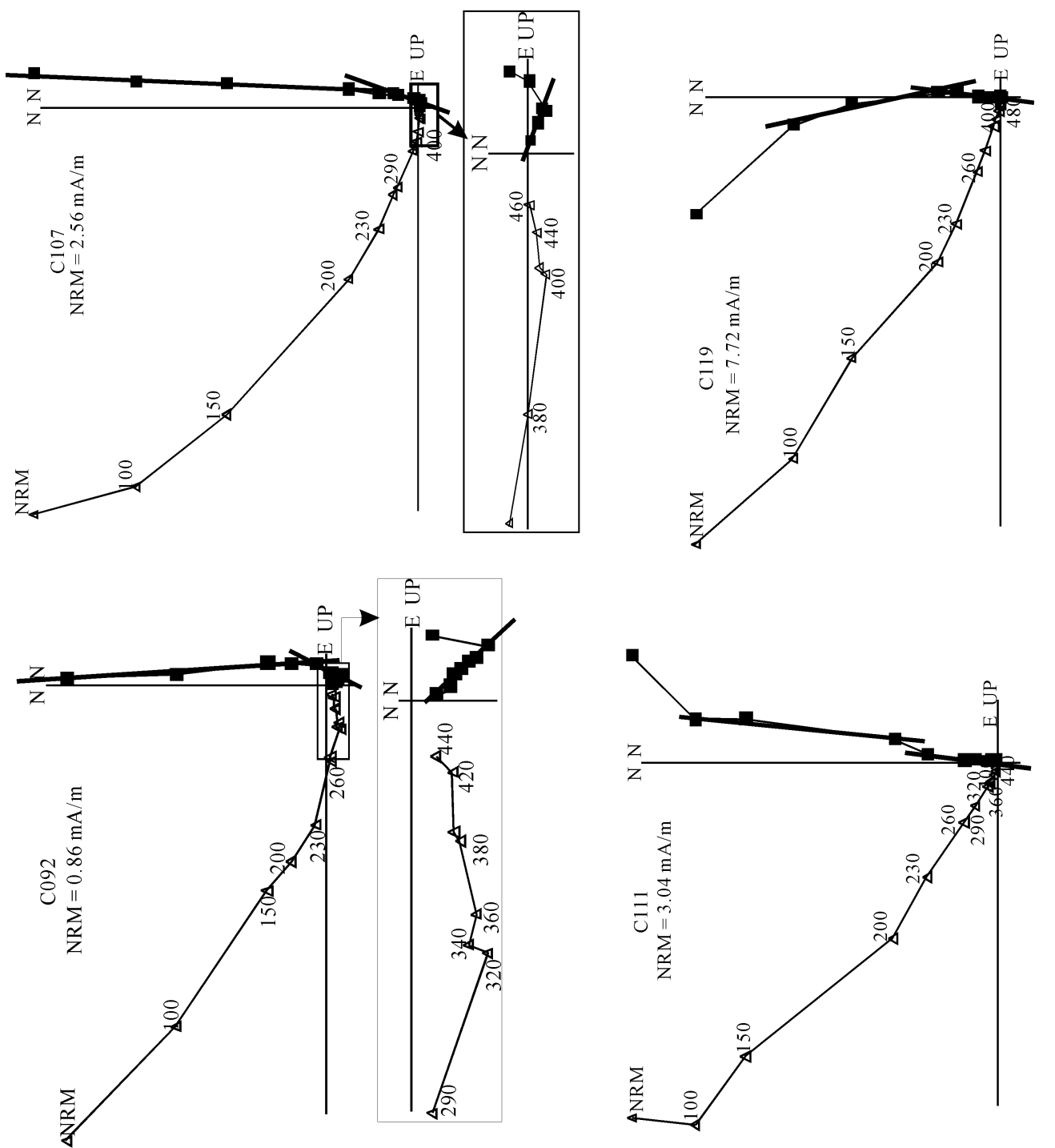

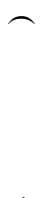
品碳 世业

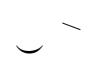

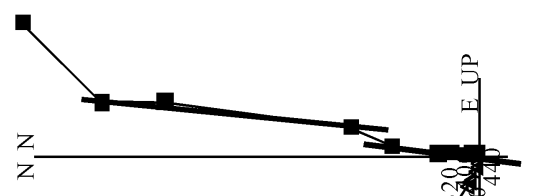
出装

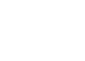
紫绖 枈亜 发兴

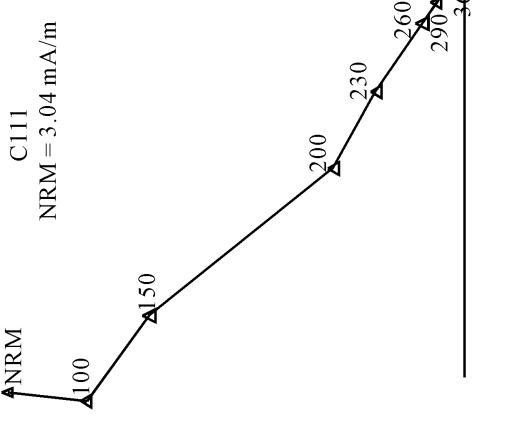

禁

递

$\vdash$ 宊

紧

㭖 嘫

惠

㗁掊

莽典

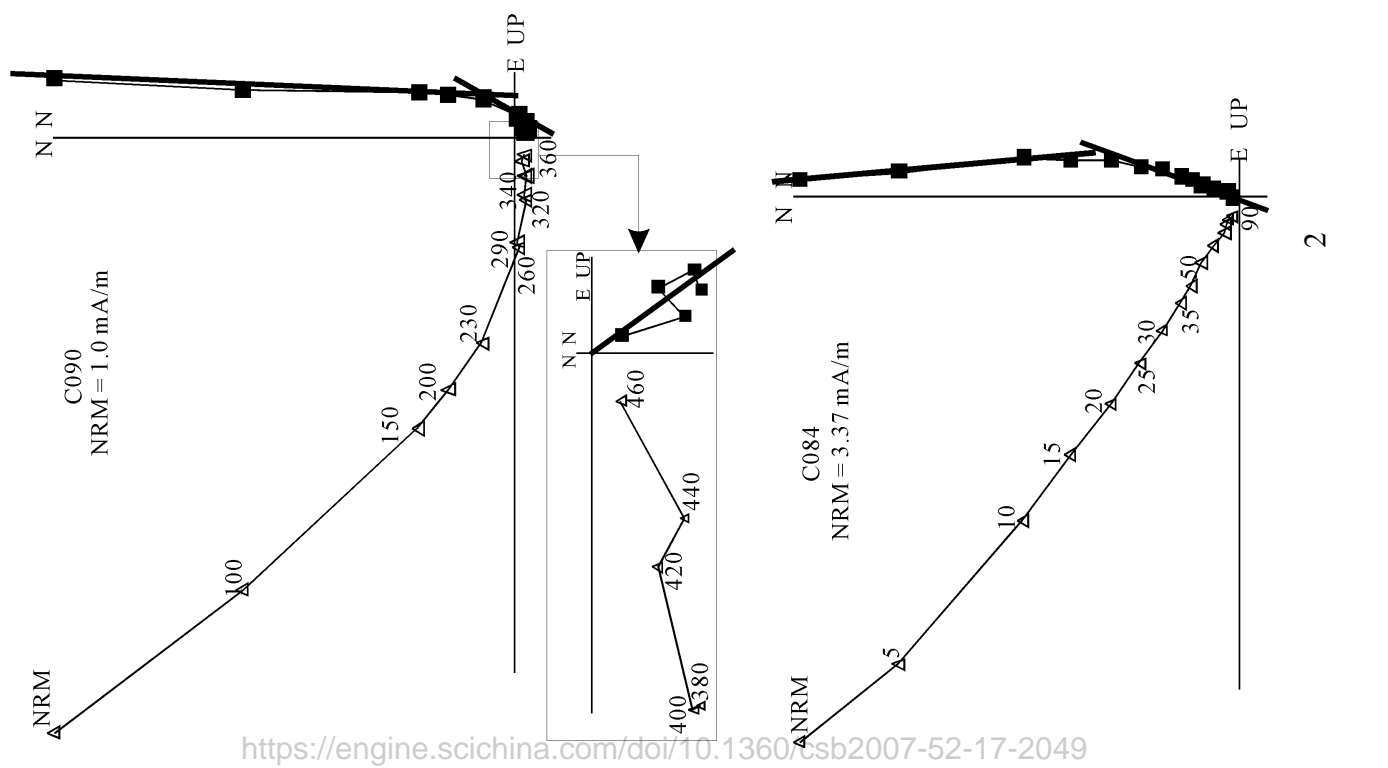


表 1 重庆万州中三叠系巴东组中高温剩磁分量统计结果 ${ }^{a)}$

\begin{tabular}{|c|c|c|c|c|c|c|c|c|}
\hline \multicolumn{9}{|c|}{ 中温组分 } \\
\hline \multirow{2}{*}{ 采点 } & \multirow{2}{*}{$\begin{array}{c}\left.\text { 地层产状/( }{ }^{\circ}\right) \\
\text { 倾向/倾角 }\end{array}$} & \multirow{2}{*}{$n / N$} & \multicolumn{2}{|c|}{ 地理坐标下/(ํ) } & \multicolumn{2}{|c|}{ 地层坐标下/( $\left.{ }^{\circ}\right)$} & \multirow{2}{*}{$k$} & \multirow{2}{*}{$\alpha_{95}$} \\
\hline & & & $D_{\mathrm{g}}$ & $I_{\mathrm{g}}$ & $D_{\mathrm{s}}$ & $I_{\mathrm{s}}$ & & \\
\hline CQ15 & $0 / 34$ & $6 / 6$ & 20.3 & 56.8 & 12.0 & 24.0 & 623.4 & 2.7 \\
\hline CQ16 & $7 / 64$ & $6 / 6$ & 16.7 & 69.3 & 10.5 & 5.5 & 193.0 & 4.8 \\
\hline CQ17 & $7 / 64$ & $6 / 6$ & 27.6 & 71.4 & 13.6 & 8.4 & 235.5 & 4.4 \\
\hline CQ20 & $10 / 66$ & $6 / 7$ & 6.7 & 64.1 & 8.6 & -1.9 & 154.9 & 5.4 \\
\hline CQ21 & $9 / 64$ & $4 / 6$ & 7.6 & 59.7 & 8.3 & -4.3 & 1204.0 & 2.6 \\
\hline CQ23 & $10 / 69$ & $6 / 6$ & 4.3 & 70.2 & 8.1 & 1.3 & 537.1 & 2.9 \\
\hline \multirow[t]{2}{*}{ 平均 } & & $6 / 9$ & 13.6 & 65.5 & - & - & 132.3 & 5.8 \\
\hline & & & - & - & 10.2 & 5.5 & 60.7 & 8.7 \\
\hline \multirow{2}{*}{ 展平 33\% } & & & & & 11.2 & 45.2 & 226.5 & 4.5 \\
\hline & & & & & \multicolumn{4}{|c|}{ 古极 $79.3^{\circ} \mathrm{N} 219.5^{\circ} \mathrm{E}, d_{\mathrm{p}}=3.6^{\circ}, d_{\mathrm{m}}=5.7^{\circ}$} \\
\hline \multicolumn{9}{|c|}{ 高温组分 } \\
\hline CQ16 & $7 / 64$ & $5 / 6$ & 130.6 & 78.0 & 18.8 & 32.2 & 105.1 & 7.5 \\
\hline CQ17 & $7 / 64$ & $6 / 6$ & 126.6 & 78.0 & 19.2 & 31.4 & 124.4 & 6.0 \\
\hline CQ18 & $7 / 49$ & $4 / 8$ & 60.5 & 81.4 & 15.5 & 35.6 & 579.2 & 3.8 \\
\hline CQ19 & $20 / 50$ & $4 / 6$ & 67.9 & 80.4 & 28.1 & 33.6 & 225.5 & 6.1 \\
\hline CQ21 & $9 / 64$ & $4 / 6$ & 104.5 & 77.7 & 22.7 & 26.5 & 40.9 & 14.5 \\
\hline \multirow[t]{2}{*}{ 平均 } & & $5 / 9$ & 102.5 & 80.4 & - & - & 188.2 & 5.6 \\
\hline & & & - & - & 20.9 & 31.9 & 237.7 & 5.0 \\
\hline 展平 $70 \%$ & & & & & 24.2 & 49.0 & 453.0 & 3.6 \\
\hline
\end{tabular}

a) $n / N$, 参与统计的样品或采点数/所采样品或采点数. $D_{\mathrm{g}} / I_{\mathrm{g}}, D_{\mathrm{s}} / I_{\mathrm{s}}$, 分别为地理坐标和地层坐标下偏角/倾角. $k$, Fisher 精度参数. $\alpha_{95}, 95 \%$ 置 信圆半径, $d_{\mathrm{m}} / d_{\mathrm{p}}: 95 \%$ 置信椭圆长/短半径

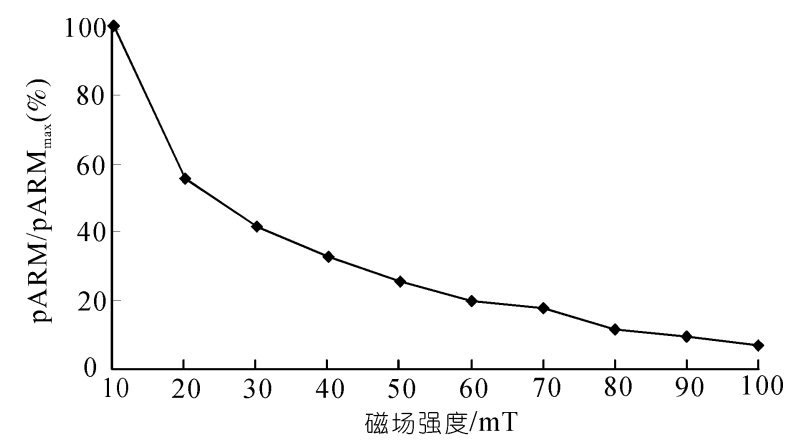

图 3 中三叠世样品的部分非磁滞剩磁 pARM: 每一间隔磁场强度下获得的部分非磁滞剩磁. $\mathrm{pARM}_{\text {max }}$ : pARM 的最大值

形中形成的重磁化. 但是, 褶皱展平 $50 \%$ 时的古地磁 倾角 $\left(59^{\circ} \pm 2^{\circ}\right)$ 与白严纪的参考倾角 $\left(48.1^{\circ} \pm 2^{\circ}\right)$ 明显不 一致，在 95\%置信范围内取褶皱展平至 $70 \%$ 时, $k=$ 453.0 (统计上与 $k_{\max }$ 没有区别), 偏角和倾角为 $D=$ $24.2^{\circ}, I=49.0^{\circ}\left(\alpha_{95}=3.6^{\circ}\right.$, 与白严纪参考古地磁倾角 最接近), 对应古地磁极位置 $69.2^{\circ} \mathrm{N}, 195.5^{\circ} \mathrm{E}, d_{\mathrm{p}}=$ $3.1^{\circ}, d_{\mathrm{m}}=4.8^{\circ}$ (图 4). 与扬子地块白严纪参考极 ${ }^{[20]}$ 对 比, 可见在褶皱变形前期, 自此同褶皱重磁化组分获 得以后, 该地区经历了 $12.8^{\circ} \pm 3.5^{\circ}$ 的顺时针旋转. 而 由中温重磁化组分已确定变形后期没有旋转, 所以
该地区的旋转发生在褶䏢的过程中且在变形的中期.

严格意义上, 弯山构造包括褶狓和褶波以后的 旋转这一特定变形过程 ${ }^{[21]}$, 即后来的旋转使原来褶 皱轴的方向改变, 引起了部分造山褶皱带的弯曲. 前 人发表的有关褶皱带旋转的古地磁结果都来自于褶 皱前获得的特征剩磁, 如Huang和Opdyke ${ }^{[7,8]}$ 对湖北 巴东、蒲圻、远安和湖南桑植附近的中三叠系研究; Tan等人 ${ }^{[11]}$ 对湖北香溪早三叠系的研究. 但这些特征 剩磁所揭示的旋转也可能发生在褶䏢以前, 所以仅 能说明褶䏢带发生弯山构造运动的可能性. 由于没有 明确的旋转与褶䏢的时间关系(旋转发生在褶皱之前 或之后还是同时发生)的证据, 中扬子褶皱带的弯曲 是否为弯山构造并不能确定 ${ }^{[11]}$, 而本文所揭示的发生 于褶皱中期的 $12.8^{\circ} \pm 3.5^{\circ}$ 的顺时针旋转证实中扬子褶 皱带万州地区的弯曲至少部分是弯山构造所造成.

早、中三叠世古地磁研究 ${ }^{[7,11]}$ 显示, 万州地区以 东 150 200 km的湖北巴东和香溪地区经历过约 $30^{\circ}$ 的顺时针旋转. 虽然目前还不能排除部分旋转发生 于褶坡前的推覆运动时期, 至少部分旋转是发生在 褶皱的同时. 而且由于构造变形是由东向西逐渐变 晚, 当西部万州地区遭受褶皱变形并发生旋转时, 巴 


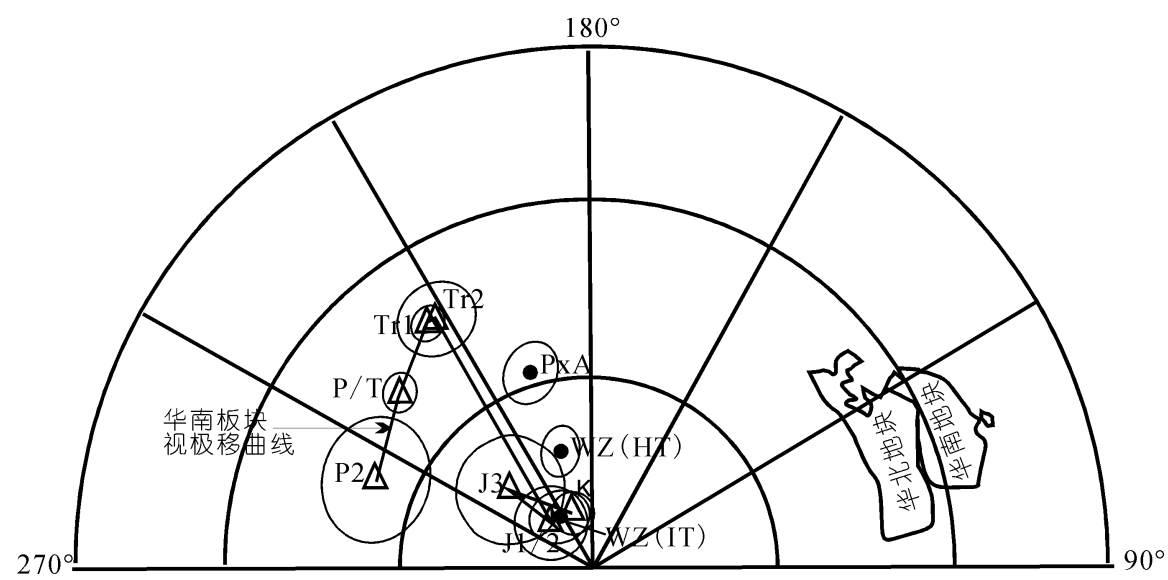

图 4 重磁化极点投影

$\mathrm{WZ}(\mathrm{IT}) / \mathrm{WZ}(\mathrm{HT})$, 中三叠系中温/高温重磁化. PxA, 湖北中三叠世蒲祈组重磁化组分 [新分析结果. 华南板块视极移曲线: P2 $\mathrm{J} 3$, 引自文献 [10]; K, 引自文献 [20]

东和香溪地区很可能在褶皱中甚至褶䏢以后发生进 一步的旋转. 因此, 我们认为, 扬子褶䏢带中万州-香 溪段部分弯曲是由于弯山构造引起的.

从华南-华北地块剪刀型碰撞拼贴模式 ${ }^{[4,22]}$ 来看, 中扬子褶皱带东部应该更可能发生过显著的顺时针 旋转. 湖北蒲圻地区中侏罗世花家湖群与晚侏罗世 马架山组不整合, 早白严世灵乡组与晚侏罗世马架 山组不整合接触, 早白严世大寺组与灵乡组亦不整

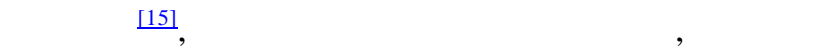
可能一直持续到白严纪. 然而, 目前来自这一地区的 古地磁数据并不多. 唯有 Huang 和Opdyke $\mathrm{e}^{[7]}$ 报道了来 自中扬子褶皱带东端, 湖北蒲圻的中三叠世古地磁 结果. 最初的解释认为, 该地区没有发生过明显的构 造旋转. 我们对中三叠系蒲圻组重磁化古地磁数据 ${ }^{[7]}$ 同上进行展平模拟重新分析. 褶皱展平至 $16 \% \pm 18 \%$ 精度参数 $k$ 达到最大值 $k_{\text {max }}=67.5$, 偏角和倾角为 $D=$ $34.4^{\circ}, I=41.5^{\circ}, \alpha_{95}=6.8^{\circ}$. 可见, 此重磁化组分获得 于褶皱末期或褶皱以后. 结合本地区地层接触关系, 我们更倾向于此重磁化获得于白严纪. 在 95\%置信 范围内取褶皱展平至 $10 \%, k=67.1$, 偏角和倾角为 $D$ $=38.9^{\circ}, I=46.8^{\circ}, \alpha_{95}=6.8^{\circ}$, 对应古地磁极位置 $56.1^{\circ} \mathrm{N}, 196.9^{\circ} \mathrm{E}, d_{\mathrm{p}}=5.7^{\circ}, d_{\mathrm{m}}=8.8^{\circ}$ (图 4). 与扬子地 块白严纪参考极 ${ }^{[20]}$ 对比, 该地区在褶皱变形末期重 磁化以后经历了 $27.5^{\circ} \pm 5.8^{\circ}$ 的顺时针旋转. 而最近 Tan等人 ${ }^{[11]}$ 的分析明确指出, 该地区发生过显著的 (大于 $50^{\circ}$ )顺时针旋转. 因此, 蒲圻地区在褶皱的同 时或褶皱前的推覆作用时期都可能发生过一定程度 的顺时针旋转, 而很可能 $50 \%$ 以上的构造旋转是由
于弯山构造导致的.

以上分析显示中扬子部分地区发生了弯山构造. 那么在扬子地块北部弯山构造是否具有普遍性? 对 扬子地区晚二叠世到中三叠世地层近 20 年来古地磁 研究的偏角数据标在图 1(b)中(具体讨论见文献 [11]). 通常采用分析褶皱带内不同部位古地磁偏角和褶坡 走向的相关性来验证褶皱带弯曲的成因 [23,24]. Yang 和Besse $\mathrm{e}^{[10]}$ 通过古地磁偏角和褶皱走向方位的比较, 结果没有显示弯山构造的存在. 最近Tan等人 ${ }^{[11]}$ 研究 表明, 这些古地磁数据中有一组数据(图 1(b)中数字 标记)所反映的相对旋转量跟褶坡轴走向具有显著的 相关性, 对褶皱轴走向原始方位的差异性经过校正 后, 相关性唯一. 目前为止, 明显的顺时针构造旋转 主要来自中扬子地区, 但是因为缺乏对构造旋转时 限的约束, 还不能形成关于中扬子地区普遍的弯山 构造的结论 ${ }^{[11]}$.

Su等人 ${ }^{[25]}$ 对中下扬子地区湖北南漳、江苏南京 等地的古地磁研究显示这些地区没有明显的旋转, 因此在提出的华南地块构造模型中指出, 沿扬子地 块北部边缘 70 225 km内为一无变形的稳定带, 而内 部中生代褶䏢带相对北部稳定带经历了一定的顺时 针旋转. 但目前中扬子地区仅南漳和远安 ${ }^{[8]}$ 地区古 地磁资料显示没有旋转, 且这一地区存在地层的不 整合接触 ${ }^{[15,16]}$ 和褶皱变形. 万州靠近秦岭造山带, 恰 在 $\mathrm{Su}$ 等人定义的无变形稳定带内, 本次研究, 白严纪 重磁化显示了万州-云阳地区弯山构造的存在. 因此, 是否可以笼统的划分一无变形稳定带值得商榷, 尤 其在中扬子褶坡带的东部还需进一步开展工作，以 
深入了解褶皱带的变形过程.

\section{2 华南-华北地块的拼贴固结时间}

中国东部包括两个主要的陆块-华北地块和华南 地块. 从 20 世纪 80 年代McElhinny等人 ${ }^{[26]}$ 的工作以 来, 大量的古地磁研究已经表明华南华北地块晚二 叠世到侏罗纪显著的相对运动 [4,7,9,22,27 35]. 通过视极 移曲线的比较, 两地块二叠纪末期在东部大别-苏鲁 造山带先碰撞, 随后在中生代以相对旋转的形式逐 步向西呈剪刀型拼贴 ${ }^{[4,22]}$. Yang和Besse $\mathrm{e}^{[10]}$ 根据两地 块的视极移曲线指出最终拼贴在早中侏罗世就已完 成. 许多学者的研究 ${ }^{[22,32,34,35]}$ 表明两地块在侏罗纪碰 撞拼合结束, 之后没有显示明显的相对运动. 白严纪 的古地磁研究也显示随后的陆内相对运动量很小 [20,27,32,36,37]. 而Yokoyama等人 [38]根据晚侏罗纪以来 华南和华北地块纬向相对运动认为陆内变形持续到 早白严世. 由此看来, 大部分古地磁学者认为两地块 最晚在侏罗纪拼贴固结为一整体.

两块体拼贴固结时限应该以华北扬子两地块间 没有相对运动为准 [33]. 古地磁极移曲线是研究块体 碰撞拼贴过程的有效手段, 但也必须注意到, 在碰撞 末期, 古地磁极在其误差范围内没有分辨几百公里 尺度相对运动的能力, 用于确定具体过程的时限, 其 精度是不高的, 有必要参考其他地质记录的资料. 扬 子褶䏢带内部与华南-华北地块碰撞相关的构造变形 特征以及同构造重磁化事件也许能给出华南-华北地 块拼贴固结时间更好的约束.

扬子褶皱带顺时针旋转被认为与华南华北地块 碰撞拼贴 $[2,5,7,11]$ 、(狭义)华南地块与扬子地块的碰撞 拼贴 ${ }^{[9]}$ 或太平洋板块向华南地块的俯冲有关 ${ }^{[7,8]}$. 在 中扬子褶皱带褶皱轴大致沿东西方向展布, 所反映 的南北向主压应力方位与太平洋板块西北方向的俯 冲不一致, 而与华南-华北地块在碰撞后期华北地块 向华南地块的南向构造挤入作用方向吻合. 本次研 究从三叠系地层中分离出白严纪褶皱过程中 2 个不 同时期的重磁化分量, 确定了万州地区在白严纪褶 皱的同时发生了顺时针旋转. 湖北蒲圻地区可能在 侏罗纪或白严纪褶皱后经历了类似的顺时针旋转. 首先蒲圻和万州分别处于中扬子褶皱带的东西两端, 由地层的不整合关系 ${ }^{[15,16]}$, 万州地区中生代地壳变 形发生在晚侏罗纪末期至早白严纪晚于东部蒲圻地 区中侏罗纪末期至白严纪的褶皱变形 [15]. 两地构造 变形的时间先后是和华北-华南两地块自东向西呈剪
刀型碰撞拼合 ${ }^{[4,22]}$ 以及华北地块的构造挤入模式 ${ }^{[33,39]}$ 相吻合的. 中扬子褶䏢带东部地区比西部地区发生 过较大的顺时针旋转, 也说明了华北华南两陆块间 的古海洋消失后陆内变形持续发生. 这一持续变形 很可能是华南地块的俯冲和东部地区华北地块的刚 性楔入所引起的. 总之, 中扬子褶䏢带所经历的主压 应力方向以及构造变形时序和旋转量从东向西变晚 和变小的特征都和华南-华北的碰撞拼贴模式一致. 本次研究发现的万州地区白严纪同褶皱重磁化事件 很可能就是在华南华北两地块碰撞拼合的最后阶段 获得的.

Tan和Kodama ${ }^{[40]}$ 注意到, 在恢复相对旋转后, 扬 子地块北部存在显著的岩石圈块体亏损, 说明两块 体间的拼贴还经历过华北地块向华南地块的构造挤 入作用. 正如Yokoyama等人 ${ }^{[38]}$ 根据扬子地块晚侏罗 纪古地磁极指出从晚侏罗纪到早白严纪扬子地块相 对华北地块仍有一定的顺时针旋转 $\left(6.8^{\circ} \pm 9.8^{\circ}\right)$ 和北向 位移 $\left(9.8^{\circ} \pm 7.4^{\circ}\right)$. 而根据Xu等人 ${ }^{[41]}$ 的研究, 中生代郯 庐断裂带构造活动主要发生在晚侏罗纪末期或早白 严纪早期(约140 130 Ma). 年代学 ${ }^{[42]}$ 的研究表明了 炏庐断裂带早白严世(128 132 Ma)大规模走滑运动 的存在. 太平洋板块的俯冲作用也可能导致了郯庐 断裂带在晚侏罗纪末期或早白严纪早期左旋滑移, 这或许是华北地块在该时期向华南地块刚性楔入并 引起中扬子地区构造旋转的根源.

因此我们认为, 中扬子地区晚侏罗世末期和早 白严世的褶皱造山(包括弯山构造)很可能就是华南华北地块碰撞拼贴过程的最后一幕, 其拼贴过程很 可能一直持续到早白严世早期.

\section{4 结论}

（ｉ）万州地区中三叠世巴东组在白严纪褶皱的 前期获得一重磁化方向, 随后在褶皱的中期发生了 $12.8^{\circ} \pm 3.5^{\circ}$ 顺时针旋转. 褶皱后期又获得一重磁化组 分, 之后没有发生明显的旋转. 结合前人结果表明, 扬子褶䏢带万州-香溪段至少部分弯曲是由弯山构造 所引起; 东部湖北蒲圻地区在褶䏢变形末期重磁化 以后经历了 $27.5^{\circ} \pm 5.8^{\circ}$ 的顺时针旋转, 无疑该地区也 属于弯山构造, 而剩余约 $25^{\circ}$ 的顺时针旋转可能发生 在褶皱同时或褶皱前的推覆运动时期.

(ii) 中扬子地区褶皱造山等构造作用从中侏罗 纪一直延续到早白严纪, 且其构造特征与华北-华南 地块的拼贴模式相吻合, 表明华南-华北碰撞可能一 


\section{直持续到早白严世早期.}

\section{参考文献}

1 Carey S W. The orocline concept in geotectonics. Papers and proceedings of the Royal Society of Tasmania, 1955, 89: 255-289

2 李正祥, 方大钧, Powell C M, 等. 华南中生代以来弯山构造的 发育和地块相对旋转一一地质和古地磁证据. 科学通报, 1996, 41(5): $446-450$

3 Marshak S. Kinematics of orocline and arc formation in thinskinned orogens. Tectonics, 1988, 7: 73-86

4 Zhao X, Coe R S. Paleomagnetic constrains on the collision and rotation of north and south China. Nature, 1987, 327: 141144[DOI]

5 Steiner M, Ogg J, Zhang Z, et al. The Late Permian/Early Triassic magnetic polarity time scale and plate motions of China. J Geophys Res, 1989, 94(B6): 7343-7363

6 Dobson J P, Heller F. Triassic paleomagnetic results from the Yangtze Block, S E China. Geophys Res Lett, 1993, 20: 1391-1394

7 Huang K, Opdyke N D. Paleomagnetism of Middle Triassic redbeds from Hubei and northwestern Hunan provinces, South China. Earth Planet Sci Lett, 1996, 143: 63-79[DOI]

8 Huang K, Opdyke N D. Middle Triassic paleomagnetic results from central Hubei province, China and their tectonic implications. Geophys Res Lett, 1997, 24(13): 1571-1574[DOI]

9 Hsue K J, Sun S, Li J L, et al. Mesozoic overthrust tectonics in South China. Geology, 1988, 16(5): 418-421[DOI]

10 Yang Z, Besse J. New Mesozoic apparent polar wander path for south China: Tectonic consequences. J Geophys Res, 2001, 106(B5): 8493-8520[DOI]

11 Tan X, Kodama K P, Gilder S, et al. Palaeomagnetic evidence and tectonic origin of clockwise rotations in the Yangtze fold belt, South China Block. Geophys J Int, 2007, 168(1): 48-58, doi: 10.1111/j.1365-246X.2006.03195.x[DOI]

12 Yan D, Zhou M, Song H, et al. Origin and tectonic significance of a Mesozoic multi-layer over-thrust system within the Yangtze Block (South China). Tectonophysics, 2003, 361: 239-254[DOI]

13 Liu S, Heller P L, Zhang G. Mesozoic basin development and tectonic evolution of the Dabieshan orogenic belt, central China. Tectonics, 2003, 22(4): 1038, doi: 10.1029/2002TC001390

14 Meng Q, Zhang G. Timing of collision of the North and South China blocks: controversy and reconciliation. Geology, 1999, 27: 123126[DOI]

15 湖北省地质矿产局. 湖北省区域地质志. 北京: 地质出版社, 1990

16 四川省地质矿产局. 四川省区域地质志. 北京: 地质出版社, 1991

17 Kirschvink J L. The least-squares line and plane and the analysis of palaeomagnetic data. Geophys J R Astron Soc, 1980, 62: 699-718

18 Fisher R A. Dispersion on a sphere. Proc R Soc London Ser A-Math Phys Eng Sci, 1953, 217: 295—305

19 Watson G S, Enkin R J. The fold test in paleomagnetism as a parameter estimation problem. Geophys Res Lett, 1993, 20(19): 2135-2137

20 Morinaga H, Liu Y. Cretaceous paleomagnetism of the eastern South China Block: Establishment of the stable body of SCB. Earth Planet Sci Lett, 2004, 222: 971—988[DOI]

21 Stamatakos J, Hirt A M. Paleomagnetic considerations of the development of the Pennsylvania Salient in the Central Appalachians. Tectonophysics, 1994, 231(4): 237-255[DOI]

22 Enkin R J, Yang Z, Chen Y, et al. Paleomagnetic constraints on the Geodynamic history of the major blocks of China from the Permian to the Present. J Geophys Res, 1992, 97: 13953-13989

23 Schwartz S Y, van der Voo R. Paleomagnetic evaluation of the orocline hypothesis in the central and southern Appalachians. Geophys
Res Lett, 1983, 10: 505-508

24 Butler R F, Richards D R, Sempere $T$, et al. Paleomagnetic determinations of vertical-axis tectonic rotations from Late Cretaceous and Paleocene strata of Bolivia. Geology, 1995, 23(9): 799-802[DOI]

25 Su L, Yang Z, Sun Z, et al. Regional deformational features of the South China Block inferred from Middle Triassic palaeomagnetic data. Geophys J Int, 2005, 162: 339-356[DOI]

26 McElhinny M W, Embleton B J J, Ma X H, et al. Fragmentation of Asia in the Permian. Nature, 1981, 293: 212-216[DOI]

27 Lin J L, Fuller M, Zhang W Y. Preliminary Phanerozoic polar wander paths for the North and South China blocks. Nature, 1985, 313: 444-449[DOI]

28 Yang Z Y, Ma X H, Besse J, et al. Palaeomagnetic results from Triassic sections in the Ordos basin, North china. Earth Planet Sci Lett, 1991, 104: 258-277[DOI]

29 杨振宇, 马醒华, 孙知明, 等. 华北地块显生宙古地磁视极移曲线 与地块运动. 中国科学 D 辑: 地球科学, 1998, 28(增刊 I ): 44一56

30 Opdyke N D, Huang K, Xu G, et al. Paleomagnetic results from the Triassic of the Yangtze platform. J Geophys Res, 1986, 91(B9): 9553-9568

31 Gilder S A, Courtillot V. Timing of the north-south China collision from new middle to late Mesozoic paleomagnetic data from the North China Block. J Geophys Res, 1997, 102: $17713-$ 17727[DOI]

32 吴汉宁, 吕建军, 朱日祥, 等. 扬子地块显生宙古地磁视极移曲 线及地块运动特征. 中国科学 D辑: 地球科学, 1998, 28(增刊 I): $69-78$

33 Gilder S A, Leloup P, Courtillot V, et al. Tectonic evolution of the Tancheng-Lujiang (Tan-Lu) fault via Middle Triassic to Early Cenozoic paleomagnetic data. J Geophys Res, 1999, 104(B7): 15365-15390[DOI]

34 Uno K, Huang B C. Constraints on the Jurassic swing of the apparent polar wander path for the North China Block. Geophys J Int, 2003, 154: 801-810[DOI]

35 Fang D J, Tan X D, Guo Y, et al. Paleomagnetism and tectonic evolution in Mesozoic for North China Plate. In: Wiley T J, Howell D G, Wong F L, eds. Circum-Pacific Council for Energy and Mineral Resources, Earth Science Series 13, Terrane Analysis of China and the Pacific Rim, 1990. 359-363

36 任收麦, 朱日祥, 黄宝春, 等. 造山带内古地磁研究一以苏宏 图早白严世火山岩为例. 中国科学 D 辑: 地球科学, 2002, 32(10): 799-804

37 Sun Z M, Yang Z Y, Yang T S, et al. New Late Cretaceous and Paleogene paleomagnetic results from south China and their geodynamic implications. J Geophys Res, 2006, 111, B03101, doi: 10.1029/2004JB003455[DOI]

38 Yokoyama M, Liu Y, Halim N, et al. Paleomagnetic study of Upper Jurassic rocks from Sichuan basin: Tectonic aspects for the collision between the Yangzte Block and the North China Block. Earth Planet Sci Lett, 2001, 193: 273-285[DOI]

39 Okay I, Sengör A M C, Satir M. Tectonics of an ultrahighpressure metamorphic terrane: the Dabie Shan/Tongbai Shan orogen, China. Tectonics, 1993, 12(6): 1320-1334

40 Tan X D, Kodama K P. A new tectonic model for continental collision between the North and South China blocks. EOS Trans Am Geophys Un Spring Mtg Suppl, 1999, 80(17), S91

$41 \mathrm{Xu} \mathrm{J} \mathrm{W}$, Zhu G, Tong W X, et al. Formation and evolution of the Tancheng-Lujiang wrench fault system: A major shear system to the northwest of the Pacific Ocean. Tectonophysics, 1987, 134(4): 273-310[DOI]

42 朱光, 宋传中, 王道轩, 等. 郯庐断裂带走滑时代的 ${ }^{40} \mathrm{Ar}{ }^{39} \mathrm{Ar}$ 年 代学研究及其构造意义. 中国科学 D 辑: 地球科学, 2001, 31(3): $250-256$ 